\title{
Article
}

\section{Sleep and its association with aggression among prisoners: Quantity or quality?}

Barker, Lyndsie Fiona, Ireland, Jane Louise, Chu, Simon and Ireland, Carol Ann

Available at http://clok.uclan.ac.uk/13542/

Barker, Lyndsie Fiona, Ireland, Jane Louise ORCID: 0000-0002-5117-5930, Chu, Simon ORCID: 0000-0001-8921-4942 and Ireland, Carol Ann ORCID: 0000-0001-7310-2903 (2016) Sleep and its association with aggression among prisoners: Quantity or quality? International Journal of Law and Psychiatry, 47 . pp. 115-121. ISSN 0160-2527

It is advisable to refer to the publisher's version if you intend to cite from the work. http://dx.doi.org/10.1016/j.ijlp.2016.02.014

For more information about UCLan's research in this area go to http://www.uclan.ac.uk/researchgroups/ and search for < name of research Group>.

For information about Research generally at UCLan please go to http://www.uclan.ac.uk/research/

All outputs in CLoK are protected by Intellectual Property Rights law, including Copyright law. Copyright, IPR and Moral Rights for the works on this site are retained by the individual authors and/or other copyright owners. Terms and conditions for use of this material are defined in the policies page.

\section{CLoK}

Central Lancashire online Knowledge www.clok.uclan.ac.uk

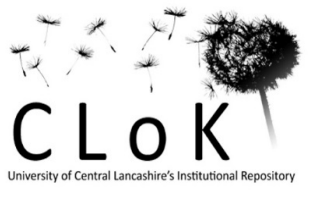


Running head: SLEEP AND AGGRESSION AMONG PRISONERS

Sleep and its association with aggression among prisoners: Quantity or quality?

Lyndsie Fiona Barker

HM Prison Service; Email: Lyndsie.Barker@hmps.gsi.gov.uk

Jane L. Ireland*, Simon Chu \& Carol A. Ireland

Ashworth Research Centre, Mersey Care NHS Trust and University of Central Lancashire, UK; Tel: + 44151473 0303; Emails: JLIreland1@uclan.ac.uk; CAIreland@uclan.a.ac.uk;

SChu@uclan.ac.uk

*Correspondence should be addressed to Jane L. Ireland, University of Central Lancashire and Ashworth Research Centre, Mersey Care NHS Trust, UK; Tel: +44 01514724525 Email: JLIreland1@uclan.ac.uk 


\title{
SLEEP AND AGGRESSION AMONG PRISONERS
}

\begin{abstract}
Objective: The current paper aims to examine the association between self-reported sleep quality and quantity and how these relate to aggression motivation and hostile cognition in a male prisoner sample. The cognitive component of sleep, namely perception, is consequently a variable of particular interest and one neglected by previous research.

Methods: Two independent studies are presented. The first comprised 95 adult male prisoners who completed a sleep quality index along with measures of implicit and explicit aggression. The second study extended this to consider aggression motivation and hostile attribution biases using a sample of 141 young male adult prisoners.

Results: In study one, sleep quantity and indicators of sleep quality were found not to associate with aggression whereas the perception of poor sleep did; those perceiving poor sleep quality were more likely than those perceiving good sleep to report they had perpetrated aggression in the previous week and to report higher levels of implicit aggression. Study two found that while increased indicators of poor sleep quality were associated with lower prosocial attribution tendencies and higher levels of reactive and proactive aggression, sleep quantity was not associated. The perception of poor quality sleep was important; those perceiving poor sleep were more likely to report higher levels of reactive and proactive aggression than those reporting good sleep.
\end{abstract}

Conclusions: Collectively the studies highlight the importance of accounting for the perception of sleep quality as an important cognitive component in understanding the association between sleep and aggression.

Keywords: sleep; aggression motivation; implicit aggression; prisoners 


\section{SLEEP AND AGGRESSION AMONG PRISONERS}

Sleep and its association with aggression among prisoners: Quantity or quality?

Sleep quality and quantity can impact on cognition, emotion (e.g. Pilcher, Ginter \& Sadowsky, 1997; Hyyppa, Kronholm \& Mattlar, 1991; Koffel \& Watson, 2009) and psychosocial functioning, including relationships (Tavernier \& Willoughby, 2014). Poor sleep is known to adversely affect health related quality of life, a concept capturing physical, emotional, mental, social and behavioural components of well-being (Roeser, Eichholz, Schwerdtle, Schlarb \& Kübler, 2012a). In non-clinical populations good sleep quantity and quality is correlated with improved health (e.g. Bellec, 1973; Hyyppa et al, 1991). Good sleep quality has, however, been found to relate better to measures of health and well being than sleep quantity, including both depression and anger (Pilcher et al, 1997). In addition, sleep difficulties, including insomnia, poor sleep quality, hypersomnia, fatigue and sleepiness have all been related to symptoms of anxiety and depression; hypersomnia, fatigue and sleepiness related to depression and anxiety more strongly than the other elements and in particular to depression. This was expected since depression can be characterised by such symptoms (e.g. Koffel \& Watson 2009). Indeed, the association between sleep difficulties and psychiatric disorders (e.g. depression, anxiety, post traumatic stress disorder, schizophrenia, and substance related disorders where there is withdrawal and/or current use), have long been recognised (Benca, 1996). The importance of sleep quality has been increasingly identified as an important consideration (Benca, 1996; Tavernier \& Willoughby, 2014; Magnée et al, 2015). Research to date has, however, focused primarily on non-forensic populations.

There is reason to consider the importance of examining sleep in forensic populations as a particular area of concern. Within closed forensic environments, such as prisons, psychosocial and socio-cultural factors may contribute to sleep challenges (Elger \& Sekera, 


\section{SLEEP AND AGGRESSION AMONG PRISONERS}

2009; Ireland \& Culpin, 2006). For example, incompatible sleeping behaviours are reported within prison settings where beds become places to sit, watch TV, and eat meals but not solely to sleep (Ireland \& Culpin, 2006). Environmental factors such as noise, lack of physical activity, heat, cold and boredom can also contribute to reducing sleep quantity and are noted components of institutional living (Levin \& Brown, 1975). Brooke, Taylor, Gunn and Maden (1998) extend this by suggesting prisoners' experience increased insomnia as a result of a high prevalence of substance misuse and associated withdrawal symptoms, including insomnia. Thus there is sufficient evidence based on the limited research to date to suggest that closed environments such as prisons can serve to promote poor sleep as a product of the environment and the individual's housed within (Elger \& Sekera, 2009; Ireland \& Culpin, 2006).

Sleep deprivation is known to affect cognitive functioning (Brand, Hatzinger, Beck \& Holsboer-Trachsler, 2009; Durmer \& Dinges, 2005) and emotional management capabilities (Dahl, 2006; Morin, 2002; Lindberg et al, 2003a; Lindberg et al 2003b). This has been reported across samples (e.g. Lemola, Schwarz \& Siffert, 2012; Haynes et al, 2006), including with prisoners (e.g. Orme, 1972; Lindberg et al, 2003a; Lindberg et al, 2003b). Emotional and cognitive functioning challenges are expected to aggravate a range of behavioural difficulties, suggesting that an association should therefore be expected between sleep challenges and behaviour. Such challenges are certainly fundamental to our understanding of aggression with difficulties in cognitive and/or emotional functioning raising the potential for aggression (e.g. Huesmann, 1998; Anderson \& Bushman, 2002; Ireland, 2011).

Within forensic settings, aggression is of particular interest although research has concentrated on a limited range of variables such as trait aggression and trait hostility (Ireland $\&$ Culpin, 2006), both of which are associated with reports of poor sleep by prisoners. 


\section{SLEEP AND AGGRESSION AMONG PRISONERS}

Research has not considered the association between sleep and aggression motivation (i.e. reactive aggression, namely emotionally driven aggression; Kempes et al, 2005; Orobio De Castro, Merk, Koops, Veerman \& Bosch, 2005; and proactive aggression, described as more planned behaviour, Arsenio, Adam \& Gold, 2009), implicit aggression or more current hostile and prosocial attributions. In addition there has been no consideration of more current aggressive behaviours. Consequently our understanding of the dynamics between aggression and sleep is limited.

The omission to address this topic in any detail is of interest since commonly accepted theoretical understandings of aggression (e.g. General Aggression Model: GAM, Anderson \& Bushman, 2002; Integrated Model of Information Processing, Huesmann, 1988, 1998) argue for cognition and emotions as key elements in promoting an aggression response, with emphasis on the former. Both make reference to the concept of aggressive scripts, which an individual learns to apply across time resulting in a largely automatic process of selection (Anderson \& Bushmann, 2002; Huesmann, 1998). Each theory also makes reference to the role of the environment in promoting choices to engage and situational factors such as the presence of a provocation or aggressive cue. These include what are commonly referred to as Hostile Attribution Biases (e.g. Taylor, Fireman \& Levin, 2013; Orobio de Castro et al, 2003) where ambiguous social cues are interpreted in a hostile fashion.

Hostile Attribution Biases are recognised as common elements explaining the association between cognition and aggression (e.g. Ireland, 2011), with such biases often existing external to conscious awareness. Cognition of this nature is further captured by the concept of implicit cognitive processing (Stacy \& Wiers, 2010). Such processing is considered a result of associations in memory thought influenced by experiences, but not those necessarily immediately aware to an individual. The development of these associations 


\section{SLEEP AND AGGRESSION AMONG PRISONERS}

in memory is considered to have developed in the same manner as for cognitive (aggressive) scripts, namely through learning and experience.

Implicit processing can impact on emotions and behaviour, with a reported association between implicit aggressive processing and aggression in general, student and workplace samples (e.g. Todorov \& Bargh, 2002; James et al, 2005; Ireland \& Birch, 2013; Bluemke, Friedrich \& Zumbach, 2009; Frost, Ko \& James, 2007). The findings have also extended to prison samples where the more impulsive implicit processing, rather than the more cognitively effortful processing, is thought to relate to increased aggression tendencies (Ireland \& Adams, 2015).

Implicit processing is considered part of the impulsive component of the ReflectionImpulsive Model (RIM: Strack \& Deutsch, 2004). In this model the associative and reflective systems of processing co-exist. The reflective system is the most explicit element where action is via conscious deliberation and appraisal (Hofmann \& Friese, 2008). Reports of aggressive behaviour would, for example, fall within the reflective system. The impulsive element of the model is considered more automatic and associated with disposition and rehearsed learning. No research to date, however, has considered how implicit cognitive processing, namely the impulsive element of this processing system, may associate.

This more automatic (implicit) processing is also occurring in a closed setting where there are a range of environmental factors aggravating poor sleep (e.g. Levin \& Brown, 1975), situational factors ensuring aggression is considered more commonplace than in general and community settings (e.g. Ireland, 2011), with evidence for personal factors raising the risk for aggression (e.g. Hostile Attribution Biases and raised tendency towards implicit aggression). What has not been fully considered is the role of a further variable in raising the risk for unhelpful aggressive cognitions and subsequent behaviours and which 


\section{SLEEP AND AGGRESSION AMONG PRISONERS}

could add to descriptions for both the environmental and personal factors. Arguably such a variable is poor sleep.

Recent evidence has emphasised the importance of perceptions of sleep quality for a range of cognitive and behavioural outcomes (e.g. Chao, Mohlenhoff, Weiner, \& Neylan, 2014; Draganich \& Erdal, 2014; Roeser, Meuele, Schwerdtle, Kubler \& Schlarb, 2012b; Tsuchiyama, Terao, Wang, Hoaki, \& Goto, 2013). Most notable is a recent demonstration of a 'sleep placebo' effect whereby the manipulation of participants' beliefs about how well they slept the night before exerted significant effects on several measures of cognitive functioning. Irrespective of participants' own self-reported sleep quality, participants who were led to believe they had slept well performed better on a number of cognitive tests than participants who were told they had slept poorly (Draganich \& Erdal, 2014). Poor subjective perceptions of sleep quality have also been associated with a reduction in frontal lobe volume in Gulf War veterans that is independent of co morbid psychiatric conditions (Chao et al., 2014). An association between frontal lobe difficulties and aggression is well documented (Wood \& Liossi, 2014). Given that the frontal lobes are broadly implicated in executive functioning, including planning, response action and behavioural inhibition, this implies that perceptions of sleep quality may influence an individual's ability to respond appropriately to environmental and social circumstances. It is surprising therefore that there has been a lack of research into what may be a common denominator in this area, namely aggression. One fairly recent study has also linked self-reported sleep quality to hostility (as a trait characteristic) while objective measures of sleep quality were unrelated to hostility (Tsuchiyama et al., 2013). Thus, recent evidence strongly converges on the view that individuals' perceptions of the quality of their sleep may exert powerful biases on information processing. 


\section{SLEEP AND AGGRESSION AMONG PRISONERS}

Certainly, poor sleep quality and/or quantity could be expected to impact on the social information processes outlined in models such as the General Aggression Model (GAM, Anderson \& Bushman, 2002) and Integrated Model of Information Processing (Huesmann, 1988) where information becomes misinterpreted (i.e. activation of Hostile Attribution Biases) as a result of sleep contributing to poor concentration and cognitive awareness (Brand et al, 2009; Durmer \& Dinges, 2005). Indeed, those who are sleep deprived are recognised to misattribute information (Kempes et al, 2005; Aresenio \& Lmerise, 2004; Arsenio et al, 2009). It could also be speculated that the reflective system of the Reflective-Impulsive Model (RIM: Strack \& Deutsch, 2004) may become impaired by poor sleep, resorting therefore to more use of the impulsive component of this system within which implicit (aggressive) processing resides.

The current studies aim to explore these issues in more detail by examining the quantity and quality of sleep in a prison environment where the environmental factors are known to be a likely aggravator of poor sleep; where situational factors indicate the risk for aggression is higher; and where personal factors such as a raised tendency towards aggressive cognition, aggression and poor emotional regulation are deemed elevated. The current study aims to examine if sleep quantity and/or quality, and specifically perceptions of sleep quality, represent factors which may predict elevated levels of aggressive behaviour and cognition in such a sample. It will add to a research base that is currently very limited and has failed to consider the importance of current aggression and the range of cognitions that may be associated with poor sleep.

Consequently, two studies were conducted to address these topics. Study One explored explicit aggression via current aggressive behaviour and implicit processing in relation to sleep quality and quantity. Study Two extended the aggression variables to address hostile attribution, prosocial attribution and aggression motivation (reactive and 


\section{SLEEP AND AGGRESSION AMONG PRISONERS}

proactive). Study One predicted that those reporting poor sleep quality and quantity would report higher current levels of aggression and demonstrate a predisposition for implicit aggressive cognition. Study Two predicted that poor sleep quality and quantity would be associated with increased levels of hostile attribution biases and with both reactive and proactive aggression.

\section{Study One}

\section{Method}

\section{Participants}

Ninety-five male adult prisoners took part. Three hundred questionnaires were distributed, with 113 returned (37.6\% return rate) and 95 useable (31.5\% of the original distribution). The mean age of participants was 35.25 years (SD 10.9). Ninety-seven percent were of a White ethnic origin, $1 \%$ Black British ethnicity and 2\% Mixed ethnicity. The total time served throughout their lifetime was 79.7 months (SD 65.3), with the majority serving a current sentence of 45 to 60 months (20\%), followed by 65 to 100 months (16.8\%), 22 to 44 months (13.7\%), $101-150$ months (10.5\%), 9 to 21 months (5.3\%), 151 to 200 months (1.1\%), with the remaining sample (32.6\%)serving an indeterminate sentence. Sentence types included violent offences (40\%), sexual offences (38\%), acquisitive (11\%), drug related $(9 \%)$ and other offences $(2 \%)$.

\section{Measures}

Direct and Indirect Prisoner Checklist - Revised (DIPC-R; Ireland, 2002).This measured the extent and frequency of victimization and perpetration and contained 113 items relating to direct (overt) and indirect (subtle) aggression, with 31 items relating to general behaviours/filler items. Examples of victimization items included, 'I have been kicked by another prisoner' and 'I have been deliberately ignored'. Examples of perpetration items include 'I have called another prisoner names about their offence or charge' and 'I have 


\section{SLEEP AND AGGRESSION AMONG PRISONERS}

spread rumours about another prisoner'. As a behavioural measure it has been used extensively within prisons (e.g. Ireland \& Ireland, 2008). In the current study participants were required to complete it with regards to the last two weeks experiences.

Pittsburgh Sleep Quality Index (PSQI; Buysse, Reynolds, Monk, Berman \& Kupfer, 1989).The PSQI is a self rated questionnaire assessing sleep quality. Participants were asked to complete it with reference to the past two weeks. Five questions were removed due to their lack of relevance to a prison setting (i.e. questions relating to bed time partners or roommates) but these are not normally scored. This left four items to ascertain the overall quantity of sleep (e.g. bedtime/rising time) and 14 self rated indicators all rated broadly on a score of 0 (no difficulty) to 3 (difficulties)to produce a global score of sleep quality difficulties. The possible range of scores was $0-21$ with high scores indicating greater levels of sleep disturbance. Included within the sleep quality items was a question inviting participants to rate their perceived quality of overall sleep either as 'bad' (Fairly Bad or Very Bad) or 'good' (Fairly Good or Very Good).

Puzzle Test (Ireland \& Birch, 2013). The Puzzle Test is a variant of a word association test which incorporates cognitively effortful (less automatic) and uncontrolled (impulsive) implicit cognitive processes using two core methods: word identification and word replacement. The word identification element of the Puzzle Test is a variant of freeword association tests where instead of generating the first word that comes to mind following a cue, participants are asked to identify the first eight words that they can identify from two pre-prepared word searches, with these searches comprising aggression, nonaggressive and neutral words. It is designed to measure more impulsive cognitive responding. The word replacement element requires the insertion of a number of words into two crossword-style puzzles where there are cues in place (e.g. occasional letters: see Appendix 1). Again, it is possible to replace these words with aggressive, non-aggressive 


\section{SLEEP AND AGGRESSION AMONG PRISONERS}

and neutral words. The word replacement element of the test requires more cognitive effort to complete. It is thus less automatic in processing and is focused more on cognitively effortful implicit associations. The Puzzle Test focuses on the implicit cognitive tendency to identify aggression and also non-aggression.

Procedure

Ethical approval was obtained from both the University Ethics Committee and the Prison. Only prisoners based in the prison at the time of the study were approached. Participants were given questionnaires at the beginning of a lunchtime period so they could complete it in their cell during the lock up period. Questionnaires were collected the following morning, during movement to work. Analysis was completed using SPSS.

\section{Results}

Results regarding sleep quality and quantity are presented first, following by the aggression measures before proceeding to an analysis of relationships across variables. Table 1 presents the overall means regarding the PSQI. Table 2 presents the means and percentages regarding the DIPC and Puzzle Test overall and between those reporting perceived good and perceived poor quality sleep.

\section{<Insert Table 1 here>}

Bivariate correlations were conducted examining the association of aggression variables $^{1}$ (implicit aggression including implicit non aggression; victimisation and perpetration totals) and the reported quantity of sleep and reported indicators of sleep quality. The latter utilised a scale of indicators of good sleep as opposed to asking participants to indicate a judgement of their quality of sleep as 'good' or 'poor'. No correlations were significant (all $r \mathrm{~s} \leq .15)$. 


\section{SLEEP AND AGGRESSION AMONG PRISONERS}

<Insert Table 2 here>

In order to assess the impact of perceptions of sleep quality, the sample was divided into those who judged their sleep quality to be 'poor' and those who judged it to be 'good' based on the single item asking for individual perceptions of poor or good sleep. Those perceiving poor sleep quality were more likely than those perceiving good sleep quality to report having perpetrated aggression towards others in the past week $\left(X^{2}[1,95]=3.80, p<\right.$ .05 ; Fishers $p<.04)$. This did not, however, hold for reports of current victimisation for which there were no differences between groups $\left(X^{2}=.02 \mathrm{~ns}\right)$.

To assess the influence of perceived sleep quality on overall implicit cognition, a multivariate analysis of variance (MANOVA) was conducted with overall implicit aggression and overall implicit non-aggression as the dependent variables and perceived sleep quality (good or bad) as the between-subject factor. There was a significant multivariate effect ( $F$ $[2,92]=6.34, p<.003)$. There was a subsequent univariate effect for implicit aggression $(\mathrm{F}$ $[1,93]=11.20, p<.001)$, with those perceiving poor quality sleep being more likely to report implicit aggression than those perceiving good quality sleep. There was no effect for implicit non-aggressive tendencies $(F=.81 \mathrm{~ns})$.

A second MANOVA was employed that examined the subscales of the overall implicit totals (i.e. impulsive implicit aggression, impulsive implicit non-aggression, effortful implicit aggression and effortful implicit non-aggression). These subscales were included as dependent variables with perceived sleep quality (good or bad) again as the between-subject factor. There was a significant multivariate effect $(F[4,90]=4.31, p<.003)$, with subsequent univariate significant effects for impulsive implicit aggression $(F[1,93]=14.6, p<.0001)$ and effortful implicit aggression $(F[1,93]=4.11, p<.04)$. Those perceiving poor quality sleep were more likely to report impulsive implicit aggression and effortful implicit 


\section{SLEEP AND AGGRESSION AMONG PRISONERS}

aggression than those perceiving good quality sleep. There was no effect for impulsive or effortful implicit non-aggressive tendencies ( $F \mathrm{~s} \leq 13.2 \mathrm{~ns})$.

\section{Study Two}

\section{Overview}

The previous study indicated that perceived sleep quality was a core element in the association between sleep and aggression and not actual sleep quantity. Since the perception of sleep quality is primarily a cognitive component, study two aimed to explore if this element could be associated with the core cognitive processes associated with increased aggression, namely Hostile Attribution Biases. It aimed to extend this further to capture aggression more broadly in relation to emotionally driven (reactive) and planned (proactive) motivated aggression. As noted earlier, an association is expected between perceived sleep quality and hostility (Tsuchiyama et al, 2013) and the current study sought to examine this in more detail.

\section{Method}

\section{Participants}

Five hundred questionnaire packs were distributed with 141 returned, representing an $18 \%$ return rate. The majority of prisoners were convicted of a violent offence $(68.8 \%)$, followed by a sex offence (13.5\%), drug offences (6.4\%), acquisitive offences $(2.1 \%)$ and driving offences $(0.7 \%)$. The remaining sample was convicted of 'other' offences (e.g. motoring). The average sentence length was 31.9 months, with a mean of 8 months spent within the prison. The average age of prisoners completing the questionnaire was 19.15 years (SD 1.24), with an average sentence length of 31.9 months (SD 38.8) and average time spent on current sentence of 8.9 (SD 10.1). 
SLEEP AND AGGRESSION AMONG PRISONERS

\section{Measures}

Reactive - Proactive Questionnaire (RPQ: Raine \& Dodge, 2006). This measures the use of reactive or proactive aggression, consisting of 23 questions scored as never (0), sometimes (1) or often (2). It includes proactive and reactive items. Example questions are 'Used physical force to get others to do what you want' (proactive) and 'Yelled at others when they have annoyed you' (reactive).

Hostile Interpretations Questionnaire (HIQ from the Affect, Cognitive and Lifestyle inventory: Ireland \& Ireland, 2012). The HIQ uses a series of ten vignettes each of which present a social situation and asks the respondent to select one of four possible responses according to how they would react in that situation. There are two logically correct answers (one hostile and one pro-social) and two logically incorrect answers (neither hostile). Focus is on the logically correct answers, with one point scored for every hostile answer, one point for every pro-social answer and 0 points for a logically incorrect answer.

The PSQI was also administered as in Study One.

\section{Procedure}

As for Study One with the exception that prisoners were provided with the questionnaire packs at evening lock up as opposed to lunchtime lock up. Again, analysis was completed using SPSS.

\section{Results}

Results regarding sleep quality and quantity are presented first, followed by the hostility and aggression measures before proceeding to analysis across variables. Table 3 presents the overall means regarding the PSQI. Table 4 presents the means and percentages regarding the RPQ and HIQ overall and between those reporting perceived good and perceived poor quality sleep. 


\section{SLEEP AND AGGRESSION AMONG PRISONERS}

<Insert Table 3 here>

<Insert Table 4 here>

Bivariate correlations were conducted examining the association across variables and the reported quantity of sleep and reported indicators of sleep quality. As noted for Study 1, the latter was based on a scale identifying factors associated with sleep quality and does not ask participants to indicate a judgement of their sleep quality as 'good' or 'poor'.

Increased indicators of poor sleep quality were associated with lower levels of prosocial tendencies on the HIQ $(r=-.32, p<.003)$ and higher levels of reactive aggression on the RPQ $(r=.21, p<.05)$ and proactive aggression on the RPQ $(r=.22, p<.04)$. The quantity of sleep (i.e. hours) were not associated with the HIQ or RPQ (all $r \mathrm{~s} \leq .01$ ). Furthermore, increased prosocial tendencies were associated with decreased levels of reactive $(r=-.28, p<.001)$ and proactive aggression $(r=-.38, p<.001)$, with increased hostile tendencies associated with increased levels of reactive $(r=.28, p<.001)$ and proactive $\operatorname{aggression}(r=.25, p<.002)$.

A MANOVA was then conducted to determine if a perception of 'good' or 'poor' quality sleep was associated with prosocial and hostile tendencies (HIQ), proactive or reactive aggression (RPQ). The between-subject factor was 'good' or 'bad' quality sleep. There was a significant multivariate effect $(F[4,136]=2.44, p<.05)$, with a subsequent univariate significant effect for reactive aggression $(F[1,139]=4.98, p<.03)$ and proactive aggression $(F[1,139]=8.92, p<.003)$, with those perceiving poor quality sleep more likely to report higher levels of reactive and proactive aggression. There was no effect for prosocial ( $F=.11 \mathrm{~ns})$ or hostile $(F=.14 \mathrm{~ns})$ on the HIQ. 


\section{SLEEP AND AGGRESSION AMONG PRISONERS}

\section{Discussion}

Both studies highlight the importance of sleep quality as a variable associated with aggression in prisoners, indicating that this was consistent for adults and young adults. The perception of a poor quality sleep was consistent between studies in determining a raised risk for aggression. In study one it was associated with explicit aggression (i.e. current aggression perpetration) and with increased levels of implicit aggression. In study two it was associated with increased levels of reactive (emotional) and proactive (planned) aggression. In study two sleep quality was also more broadly linked with aggression with increased indicators of poor quality sleep associated with less prosocial tendencies and an increased tendency towards proactive and reactive aggression. The quantity of sleep did not associate with aggression in either study.

These results support the view that sleep quality, rather than quantity, is associated with aggression and more specifically that subjective perceptions of sleep quality are crucial in influencing aggressive behaviour, as well as implicit and explicit aggression cognitions. It suggests both explicit and implicit aggression are associated with poor sleep quality, suggesting that poor sleep quality could lead to impairment in both systems of the ReflectiveImpulsive Model (RIM: Strack \& Deutsch, 2004) and not just the impulsive component.

The finding that sleep quantity was unrelated to aggression is broadly consistent with research indicating that quality is more important than quantity across a range of negative (health) impacts (e.g. Pilcher et al, 1997; Benca, 1996; Magnée, et al, 2015), and psychosocial functioning (Tavernier \& Willoughby, 2014). The current research suggests that negative impacts in this instance can be specifically extended to aggression. The current studies do not therefore support the predictions made that sleep quantity would be associated with increased levels of current aggression and implicit aggression (Study 1), or with increased levels of hostile attribution biases and aggression motivation (Study 2). 


\section{SLEEP AND AGGRESSION AMONG PRISONERS}

The predictions in relation to poor sleep quality being associated with aggression motivation (reactive and proactive) were supported although the expected prediction that hostile attributions would be associated was not; only reduced prosocial attributions were associated and specifically with increased indicators of sleep quality. This finding is of interest since it suggests that although sleep quality is important, the relationship is with prosocial and not hostile attributions. It does not support previous general research that suggests that sleep deprivation and challenges can lead to misattribution (e.g. Kempes et al, 2005; Aresenio \& Lmerise, 2004; Arsenio et al, 2009), although the current research is the first to address hostile and prosocial attributions together.

What is evidenced is a role for sleep quality in the relationship with aggression. Both the General Aggression Model (Anderson \& Bushman, 2002) and the Integrated Model of Information Processing (Huesmann, 1998) could be applied here to explain how the perception of poor sleep quality or indicators of poor sleep quality could each contribute to aggression. Both models would argue that factors that are detrimental to cognitive capacity could promote perceptions of hostility. Poor sleep quality could be considered one such factor likely to impact negatively on cognitive functioning (Brand, Hatzinger, Beck \& Holsboer-Trachsler, 2009; Durmer \& Dinges, 2005), potentially promoting the initiation of Hostile Attribution Biases. Previous research suggests that even the belief that one has experienced poor sleep quality, irrespective of actual sleep quality, may be powerful enough to be harmful to cognitive processing (Draganich \& Erdal, 2014). However, study two revealed a novel finding in that it appears it is the reduction of prosocial tendencies that was associated with poor sleep quality and not increased hostility. That is, participants with poor sleep quality were less able to 'see the good' in a situation. Whilst Tsuchiyama et al. (2013) did find an association between sleep quality and hostility, their data focused on hostility as a trait characteristic (using the Cook Medley Hostility scale) and it is possible that the basis of 


\section{SLEEP AND AGGRESSION AMONG PRISONERS}

that relationship is in attenuated prosocial tendencies associated with poor sleep quality. It could be speculated therefore that reduced sleep quality encourages the reduction of a protective factor against aggression (i.e. prosocial tendencies). Indeed, study two further demonstrated how such tendencies were a likely protective factor against aggression with the tendency towards aggression increasing as prosocial tendencies decreased.

If the findings of study one are also considered, namely where the perception of poor sleep quality was associated with increased implicit aggression, it suggests that the specific cognitions that poor sleep are associating with most therefore is not hostility but reduced prosocial attributions and raised implicit aggression tendencies. This is not an area of research that has been previously captured, although it does support previous studies in nonforensic samples that indicate that sleep quality can impact broadly on cognition (e.g. Pilcher et al, Hyyppa et al, 1991; Koffel \& Watson, 2009).

Indeed, the current studies suggest it is the cognitive component of sleep, namely the perception of poor versus good sleep quality, which is crucial. This is a factor novel to the current research; it has not been considered in previous research with both current studies highlighting how this cognitive component is significant both in relation to explicit aggression (i.e. current behaviour) and aggression motivation, but not to attributions of hostility or prosocial behaviour. Its association with current aggression and both emotionally driven (reactive) and planned (proactive) aggression is important since it proposes that it is applying uniformly across aggression motivation and is not associating purely, for example, with emotionally driven aggression. Thus, the perception of sleep difficulties does not appear to be promoting emotional difficulties alone, but also more planned aggression.

This would seem to fit with findings in relation to implicit aggression where the perception of poor sleep quality seemed associated with raised levels of such aggression. Implicit aggression is considered, as noted, a core cognitive component of aggression and by 


\section{SLEEP AND AGGRESSION AMONG PRISONERS}

some argued to represent a dispositional trait (Ireland \& Adams, 2015). The current study suggests that the association between sleep and aggression can be extended beyond the most explicit assessment of aggressive dispositional traits (Ireland \& Culpin, 2006) to more implicit dispositional traits.

Dispositional tendencies, including implicit cognition, would again fit with the General Aggression Model (Anderson \& Bushman, 2002) and the Integrated Model of Information Processing (Huesmann, 1998) in suggesting a route through which aggression can be elevated. What the current study suggests is that the perception of poor sleep quality is associating with these implicit aggressive tendencies. Arguably, this could represent a route through which aggression is increasing as opposed to the hostile attribution pathway. This is though speculative since the current studies are not longitudinal and at most are able to capture associations. It does, nevertheless, point to the value in future research addressing the specific association between the perception of poor sleep quality and aggression with regards to determining what components of cognition are mediating this relationship.

It also suggests there is value in further examining the relationships between these variables in relation to other potentially contributing factors such as age. There was some consistency in findings between the sample of adults (study 1) and young adults (study 2). However, both studies were independent of each other and did not share all measures. Thus controlling for any effect of age within analyses clearly could not take place; this would require a combined sample of adults and young adults within the same study. It is an area that future research could explore in more detail to determine if there are any differences in relation to age and whether or not this could impact on the mechanism by which sleep quality and quantity may relate.

Connected to this, the current study is not without its limitations however, with the afore noted absence of longitudinal research representing one such limitation; the cross- 


\section{SLEEP AND AGGRESSION AMONG PRISONERS}

sectional nature of the current design did not allow for an investigation of causality. In addition, the current research did not utilise objective measures of sleep quality or quantity and instead relied on self-report measures of sleep. This is largely unavoidable in a prison environment where options for measuring sleep using more objective measures such as actigraphy are not possible and specific quantitative factors, such as sleep quantity, cannot therefore be confirmed. Such a limitation also applies to the other factors that we were unable to control for but, nevertheless, may have been important. Substance use is one such consideration (Magnée, et al, 2015). Although illicit drugs and alcohol are prohibited in prison settings this does not mean that access is not possible, although it does mean that relying on prisoner self-report regarding use is particularly problematic. However, substances are known to affect sleep and identifying a means of capturing this in future research, extending it to include illicit and prescribed medication, would be valuable to consider. The current study was unable to control for the impact of substances and this clearly represents a limitation that has to be accounted for.

In addition, the focus in the current studies was on cognition and there may have been advantages in also considering a role for elevated emotions as a core component. Emotions are certainly recognised as associating with sleep difficulties (e.g. Hyyppa et al, 1991; Koffel \& Watson, 2009; Lindberg et al, 2003a) and were captured only in relation to explicit aggressive emotion (i.e. reactive aggression) that is more of a trait related variable.

Consequently, future research is likely to benefit from consideration of more dynamic measures of emotion and how these associate with sleep quality and quantity.

Nevertheless, the current findings are novel, highlighting the value in exploring this area of research in more detail. The study is the first to indicate a role for the perception of sleep quality and to examine an under-researched sample, namely prisoners. The importance of this potential area of study is thus supported. The findings also have clinical significance; 


\section{SLEEP AND AGGRESSION AMONG PRISONERS}

they highlight how a perception of poor sleep quality (i.e. a cognitive variable of sleep) associates with tendencies towards aggression and (implicit) aggressive cognition. This suggests that aggression intervention programmes should capture sleep as a component of clinical interest and as part of this aim to address the perception of poor sleep quality. In particular it raises the question of whether or not promoting more positive perceptions of sleep quality or correcting misperceptions of sleep quality may have some positive impact on tendencies towards aggression. 


\section{SLEEP AND AGGRESSION AMONG PRISONERS}

References

Anderson, C.A., \& Bushman, B.J. (2002). Human Aggression. Annual Review Psychology, $53,27-51$.

Arsenio, W.F., Adam. E., \& Gold, J. (2009). Social information processing, moral reasoning, and emotion attributions: Relations with adolescents' reactive and proactive aggression. Child Development, 80, 1739-1755.

Aresenio, W.F., \& Lmerise, E.A. (2004). Aggression and moral development: Integrating social information processing and moral domain models. Child Development, 75, 9872002.

Bellec, N. B. (1973). Relationship of health practices and mortality. Preventive Medicine, 2, $67-81$

Benca, R.M. (1996). Sleep in psychiatric disorders. Sleep Disorders, 14 (4), 739 - 764

Bluemke, M., Friedrich, M., \& Zumbach, J. (2009). The influence of violent and nonviolent computer games on implicit measures of aggressiveness. Aggressive Behavior, 35, 1 $-13$.

Brand, S., Hatzinger. M., Beck. J., \& Holsboer-Trachsler. E. (2009). Perceived parenting style, personality traits and sleep patterns in adolescents. Journal of adolescence, 32 , 1189-1207.

Brooke, D., Taylor. C., Gunn. J., \& Maden. A. (1989). Substance misuse remanded to prisona treatment opportunity. Addiction, 93. 1851-1856,

Buysse, D.J., Reynolds, C.F., Monk, T.H., Berman, S.R., \& Kupfer, D.J. (1989). The Pittsburgh Sleep Quality Index: A new instrument for psychiatric practice and research. Psychiatry Research,2, 193-213.

Chao, L.L., Mohlenhoff, B.S., Weiner, M.W., \& Neylan, T.C. (2014). Associations between 


\section{SLEEP AND AGGRESSION AMONG PRISONERS}

Subjective Sleep Quality and Brain Volume in Gulf War Veterans. Sleep, 37(3), 445452.

Dahl, R. E. (1999). The Consequences of insufficient sleep for adolescents: Links between sleep and emotional regulation. PHL Delta Kappa, 354-359.

Draganich, C., \& Erdal, K. (2014). Placebo sleep affects cognitive functioning. Journal of Experimental Psychology - Learning Memory and Cognition, 40(3), 857-864.

Durmer, J.S., \& Dinges, D.F. (2005). Neurocognitive consequences of sleep deprivation. Seminars in Neurology, 25, 117-129.

Elger, B. S., \& Sekera, E. (2009). Prospective evaluation of insomnia in prison using the Pittsburgh Sleep Quality Index: Which are the factors of predicting insomnia? International journal of psychiatry in clinical practice, 13, 206-217.

Frost, B. C., Ko, C. E., \& James, L. R. (2007). Implicit and explicit personality: A test of a channeling hypothesis for aggressive behavior. Journal of Applied Psychology, $92,1299-1319$.

Haynes, P. L., Bootzin, R. R., Smith, L., Cousins, J., Cameron, M., \& Stevens, S. (2006).

Sleep and aggression in substance-abusing adolescents: Results from an integrative behavioural sleep treatment pilot programme. Sleep, 29, 512-520.

Huesmann, L.R. (1988). An information processing model for the development of aggression. Aggressive Behaviour, 14, 13-24.

Huesmann, L. R. (1998). The role of social information processing and cognitive schema in the acquisition and maintenance of habitual aggressive behavior. In R. G. Geen, \& E.

Donnerstein (Eds.), Human aggression: Theories, research, and implications for social policy(pp. 73 - 110). London, UK: Academic Press Ltd.

Hofmann, W., \& Friese, M. (2008). Impulses got the better of me: Alcohol moderates 


\section{SLEEP AND AGGRESSION AMONG PRISONERS}

the influence of implicit attitudes towards food cues on eating behaviour. Journal of Abnormal Behavior, 117, 420 - 427.

Hyyppa, M. T., Kronholm. E., \& Mattlar, C.E. (1991). Mental well being of good sleepers in a random population sample. British Journal of Medical Psychology, 64, 25-34.

Ireland, J.L. (2002). Bullying in prisons. The Psychologist, 15, 130 - 133.

Ireland, J.L., \&Adams, C. (2015). Implicit aggression among young male prisoners:

Association with dispositional and current aggression. International Journal of Law \& Psychiatry, 41, $89-94$.

Ireland, J. L., \& Ireland, C. A. (2008). Intra-group aggression among prisoners: Bullying intensity and exploration of victim-perpetrator mutuality. Aggressive Behavior, 34, $76-87$.

Ireland, J. L. (2011). Violence assessment and intervention. In G. Davey (Ed.), Applied Psychology. (291 - 316) London, UK: BPS Wiley-Blackwell.

Ireland, J. L., \& Ireland, C. A. (2012). Affect, Cognitive, and Lifestyle Assessment (ACL). The International Organisation for Forensic Practitioners (TIOFP).

Ireland, J.L., \& Birch, P. (2013). Emotionally abusive behaviour in young couples: Exploring a role for implicit aggression. Journal of Interpersonal Violence, 210, 375 - 380.

Ireland, J, L., \& Culpin, V. (2006). The relationship between sleeping problems and aggression, anger and impulsivity in a population of juvenile and young offenders. Journal of Adolescent Health, 38, 649-655.

James, L. R., McIntyre, M. D., Glisson, C. A., Green, P. D., Patton, T. W., LeBreton, J. M., Frost, B. C., Russell, S. M., Sablynski, C. J., Mitchell, T. R., \&Williams, L. J. (2005). A conditional reasoning measure for aggression. Organizational Research Methods, 8, 69-99.

Kempes, M., Matthys, W., De'Vries, H,. \& Engeland, H. (2005). Reactive and proactive 


\section{SLEEP AND AGGRESSION AMONG PRISONERS}

aggression in children. A review of theory, findings and the relevance for child and adolescent psychiatry. European Child \& Adolescent Psychiatry, 14, 11-19.

Koffel, E., Watson. D. (2009). The two-factor structure of sleep complaints and its relation to depression and anxiety. Journal of abnormal psychology, 118, 183-194.

Lemola, S., Schwarz. B., \&Stiffert. A. (2012). Interparental conflict and early adolescences' aggression: Is irregular sleep a vulnerability factor? Journal of adolescence, 35, 97105.

Levin, B, H., \&Brown. W, E. (1975). Susceptibility to boredom of jailers and law enforcement officers. Psychological Reports, 36, 190.

Lindberg, N., Tani, P., Appelberg, B., Stenberg, D., Naukkarinen, H., Rimón, R., \& ... Virkkunen, M. (2003a). Sleep among Habitually Violent Offenders with Antisocial Personality Disorder. Neuropsychobiology, 4, 198-205.

Lindberg, N., Tani, P., Appelberg, B., Naukkarinen, H., Rimón, R., Porkka-Heiskanen, T., \&Virkkunen, M. (2003b). Human impulsive aggression: a sleep research perspective. Journal of Psychiatric Research, 4, 313-324.

Magnée, E. H. B., de Weert-van Oene,G. H., Wijdeveld, T. A. G. M., Coenen, A. M. L., \& de Jong, C. A. (2015). Sleep disturbances are associated with reduced health quality of life in patients with substance use disorders. The American Journal of Addictions, 24 (6), $515-522$.

Morin, C.M. (2002). Contributions of cognitive behavioural approaches to the clinical management of insomnia. Journal of clinical psychiatry, 2, 21-26.

Orobio de Castro, B., Merk, W., Koops, W., Veerman, J.W., \&Bosch, J.D. (2005). Emotions in Social Information Processing and their relations with reactive and proactive aggression in referred aggressive boys. Journal of Clinical Child and Adolescent Psychology, 34,105-116. 


\section{SLEEP AND AGGRESSION AMONG PRISONERS}

Orme, J, E. (1972). Duration of sleep and its relationship to age, personality and psychiatric illness. British Journal of Social and Clinical Psychology, 11, 70-72.

Plicher,J, J., Ginter. D, R., \& Sadowsky, B. (1997). Sleep quality versus sleep quantity: relationships between sleep and measures of health, well being and sleepiness in college students. Journal of psychosomatic research, 42, 583-596.

Raine, A., Dodge, K., Loeber, R., Gatzke-Kopp, L., Lynam, D., Reynolds, C., StouthamerLoeber, M., \& Liu, J. (2006). The reactive-proactive aggression questionnaire: Differential correlates of reactive and proactive aggression in adolescent boys. Aggressive Behaviour, 32, 159 - 171.

Roeser, K., Eichholz, R., Schwerdtle, B., Schlarb, A. A., \& Kübler, A. (2012a). Relationship of sleep quality and health related quality of life in adolescents according to self and proxy ratings: A questionnaire survey. Frontiers in Psychiatry, 3: 76.

Roeser, K., Meule, A., Schwerdtle, B., Kubler, A., \&Schlarb, A.A. (2012b). Subjective sleep quality exclusively mediates the relationship between morningness-eveningness preference and self-perceived stress response. Chronobiology International, 29(7), 955-960.

Stacy, A.W., \&Wiers, R.W. (2010). Implicit cognition and addiction: A tool for explaining paradoxical behaviour. Annual Review Clinical Psychology, 6, 551 - 575.

Strack, F., \& Deutsch, R. (2004). Reflective and impulsive determinants of social behaviour. Personality Social Psychology Review, 8, 220 - 247.

Taylor, N.D., Fireman, G.D., \& Levin, R. (2013). Trait hostility, perceived stress and sleep quality in a sample of normal sleepers. Sleep Disorders. Epub 2013 Apr 22.doi: $10.1155 / 2013 / 735812$.

Tavernier, R \& Willoughby, T. (2014). Bidirectional associations between sleep (quality and duration) and psychosocial functioning across the university years. Developmental Psychology, 50 (3), 674. 


\section{SLEEP AND AGGRESSION AMONG PRISONERS}

Todorov, A., \& Bargh, J.A. (2002). Automatic sources of aggression. Aggressive \& Violent Behavior, 7, $53-68$.

Tsuchiyama, K., Terao, T., Wang, Y.M., Hoaki, N., Goto, S. (2013). Relationship between hostility and subjective sleep quality. Psychiatry Research, 209(3), 545-548.

Wood, R. L., Liossi, C., \& Psych, D. (2014). Neuropsychological and neurobehavioral correlates of aggression following traumatic brain injury. Journal of Neuropsychiatry and Clinical Neurosciences, 18 (3), 333 - 341. 
SLEEP AND AGGRESSION AMONG PRISONERS

Footnote

${ }^{1}$ Correlations between implicit aggression and reports of perpetration and victimisation indicated no associations between implicit aggression (including its subcomponents) and victimisation (all $r$ 's $\leq-.18$ ). Across perpetration, increased levels of perpetration were associated with increased levels of total implicit aggression $(r=.22, p=.03)$, and impulsive implicit aggression $(r=.24, p=.02)$ and with decreased levels of total implicit non$\operatorname{aggression}(r=-.26, p=.009)$ and with impulsive non- aggression $(r=-.25, p=.01)$ and effortful implicit non-aggression $(r=-.22, p=.03)$. 
Table 1.

Means and percentages for sleep quality, sleep quantity and aggression across prisoners (Study 1).

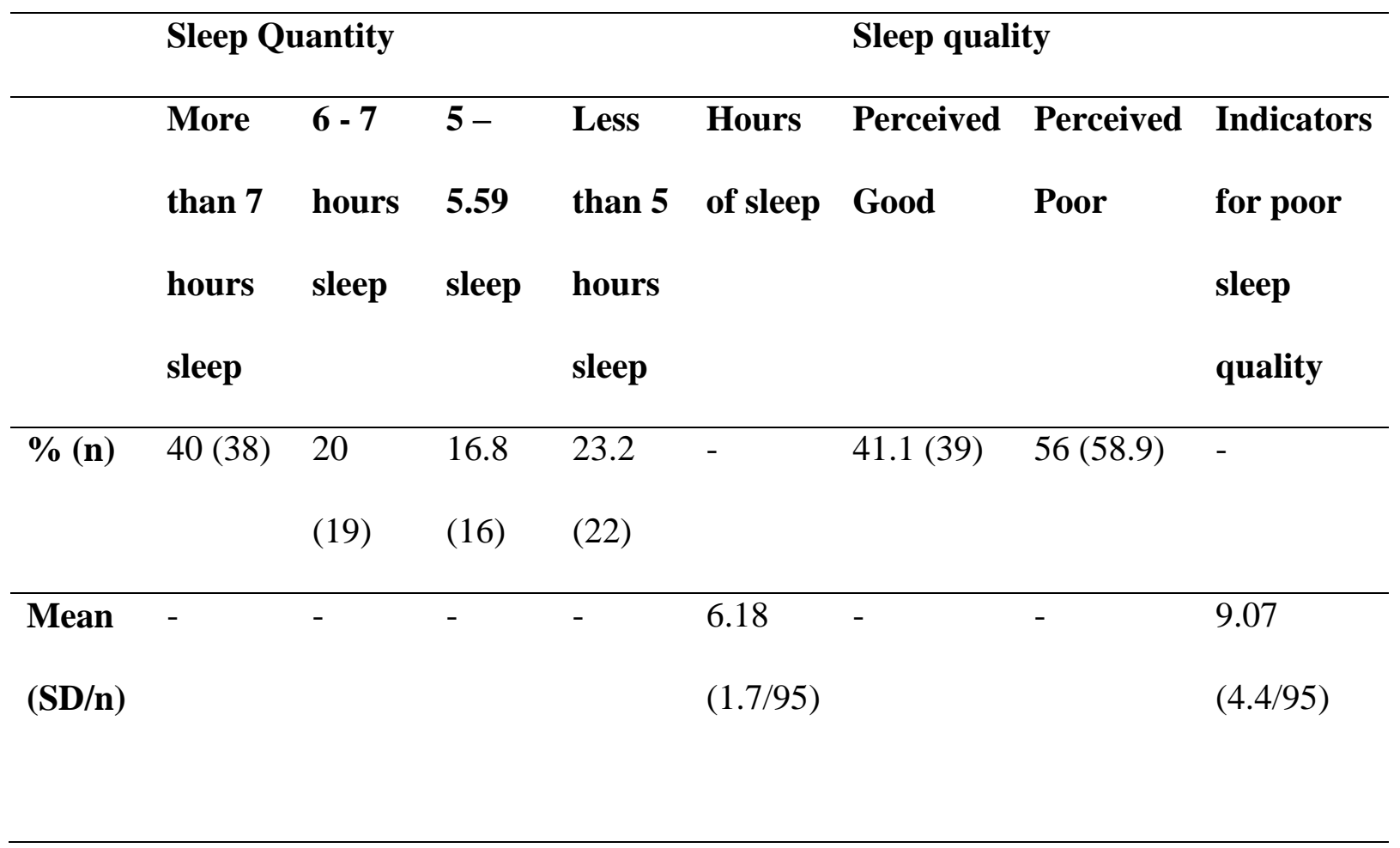


Table 2.

Means and percentages for DIPC and Puzzle Test across prisoners and those reporting perceived poor and perceived good quality sleep.

\begin{tabular}{|c|c|c|c|c|c|c|}
\hline \multirow[t]{2}{*}{ Measure } & \multicolumn{3}{|c|}{$\begin{array}{l}\text { \% reporting at least one incident } \\
\text { (n) }\end{array}$} & \multicolumn{3}{|c|}{ Mean (SD/n) } \\
\hline & Overall & $\begin{array}{l}\text { Good } \\
\text { quality } \\
\text { sleep } \\
\text { (perceived) }\end{array}$ & $\begin{array}{l}\text { Poor } \\
\text { quality } \\
\text { sleep } \\
\text { (perceived) }\end{array}$ & Overall & $\begin{array}{l}\text { Good } \\
\text { quality } \\
\text { sleep } \\
\text { (perceived) }\end{array}$ & $\begin{array}{l}\text { Poor } \\
\text { quality } \\
\text { sleep } \\
\text { (perceived) }\end{array}$ \\
\hline $\begin{array}{l}\text { Overall } \\
\text { victimisation }\end{array}$ & $72.6(69)$ & $71.8(28)$ & $73.2(41)$ & - & - & - \\
\hline $\begin{array}{l}\text { Overall } \\
\text { perpetration }\end{array}$ & $45.3(43)$ & 33.7 (13) & $53.6(30)$ & - & - & - \\
\hline $\begin{array}{l}\text { Implicit } \\
\text { aggression }\end{array}$ & - & - & - & $\begin{array}{l}10.1 \\
(4.9 / 95)\end{array}$ & $\begin{array}{l}8.17 \\
(5.28 / 39)\end{array}$ & $\begin{array}{l}11.5 \\
(4.3 / 56)\end{array}$ \\
\hline $\begin{array}{l}\text { Implicit non- } \\
\text { aggression }\end{array}$ & - & - & - & $\begin{array}{l}19.2 \\
(6.1 / 95)\end{array}$ & $\begin{array}{l}19.8 \\
(7.4 / 39)\end{array}$ & $\begin{array}{l}18.7 \\
(5.1 / 56)\end{array}$ \\
\hline $\begin{array}{l}\text { Impulsive } \\
\text { implicit } \\
\text { aggression }\end{array}$ & - & - & - & $\begin{array}{l}4.9 \\
(2.8 / 95)\end{array}$ & $\begin{array}{l}3.7 \\
(2.7 / 39)\end{array}$ & $\begin{array}{l}5.8 \\
(2.6 / 56)\end{array}$ \\
\hline $\begin{array}{l}\text { Impulsive } \\
\text { implicit non- } \\
\text { aggression }\end{array}$ & - & - & - & $\begin{array}{l}9.9 \\
(3.1 / 95)\end{array}$ & $\begin{array}{l}10.4 \\
(3.5 / 39)\end{array}$ & $\begin{array}{l}9.6 \\
(2.8 / 56)\end{array}$ \\
\hline $\begin{array}{l}\text { Effortful } \\
\text { implicit } \\
\text { aggression }\end{array}$ & - & - & - & $\begin{array}{l}5.1 \\
(2.8 / 95)\end{array}$ & $\begin{array}{l}4.4 \\
(3.1 / 39)\end{array}$ & $\begin{array}{l}5.6 \\
(2.6 / 56)\end{array}$ \\
\hline $\begin{array}{l}\text { Effortful } \\
\text { implicit non- } \\
\text { aggression }\end{array}$ & - & - & - & $\begin{array}{l}9.2 \\
(3.6 / 95)\end{array}$ & $\begin{array}{l}9.5 \\
(4.4 / 39)\end{array}$ & $\begin{array}{l}9.1 \\
(3.1 / 56)\end{array}$ \\
\hline
\end{tabular}


Table 3.

Means and percentages for sleep quality, sleep quantity and aggression across prisoners (Study 2).

\begin{tabular}{|c|c|c|c|c|c|c|c|c|}
\hline & Sleep C & lantity & & & & Sleep qual & & \\
\hline & More & $6-7$ & $5-$ & Less & Hours & Perceived & Perceived & Indicators \\
\hline & than 7 & hours & 5.59 & than 5 & of sleep & Good & Poor & for poor \\
\hline & hours & sleep & sleep & hours & & & & sleep \\
\hline & sleep & & & sleep & & & & quality \\
\hline$\%(n)$ & 30.5 & 32.6 & 13.5 & 23.4 & - & $38.3(54)$ & $61.7(87)$ & - \\
\hline & (43) & (46) & (19) & (33) & & & & \\
\hline Mean & - & - & - & - & 6.31 & - & - & 9.80 \\
\hline$(\mathrm{SD} / \mathbf{n})$ & & & & & $(2.2 / 141)$ & & & $(4.1 / 141)$ \\
\hline
\end{tabular}


Table 4.

Means and percentages for RPQ and HIQ across prisoners and those reporting perceived poor and perceived good quality sleep.

\begin{tabular}{|c|c|c|c|}
\hline Measure & Mean (SD/n) & & \\
\hline & Overall & $\begin{array}{l}\text { Good quality } \\
\text { sleep } \\
\text { (perceived) }\end{array}$ & $\begin{array}{l}\text { Poor quality } \\
\text { sleep } \\
\text { (perceived) }\end{array}$ \\
\hline HIQ - Hostile & $5.3(2.3 / 141)$ & $5.22(2.2 / 54)$ & $5.36(2.4 / 87)$ \\
\hline HIQ - Prosocial & $4.1(2.3 / 141)$ & $4.1(2.2 / 54)$ & $4.0(2.3 / 87)$ \\
\hline RPQ - Reactive & $8.9(5.8 / 141)$ & $7.6(5.6 / 54)$ & $9.77(5.7 / 87)$ \\
\hline RPQ - Proactive & $4.05(4.3 / 141)$ & $2.7(3.2 / 54)$ & $4.9(4.9 / 87)$ \\
\hline
\end{tabular}




\section{Appendix 1}

Example of one of two tests from the Puzzle Test designed to assess cognitively effortful implicit aggressive processing (@Taken from Ireland \& Birch, 2013).

Your aim below is to complete as many of the white boxes as you can using a word that fits. It does not matter what word you use but it must be a word (not a name or place) and include the letters already in the grid. You must not write in the shaded areas. One word has already been completed to help start you off. Just try and fill in as many as you can.

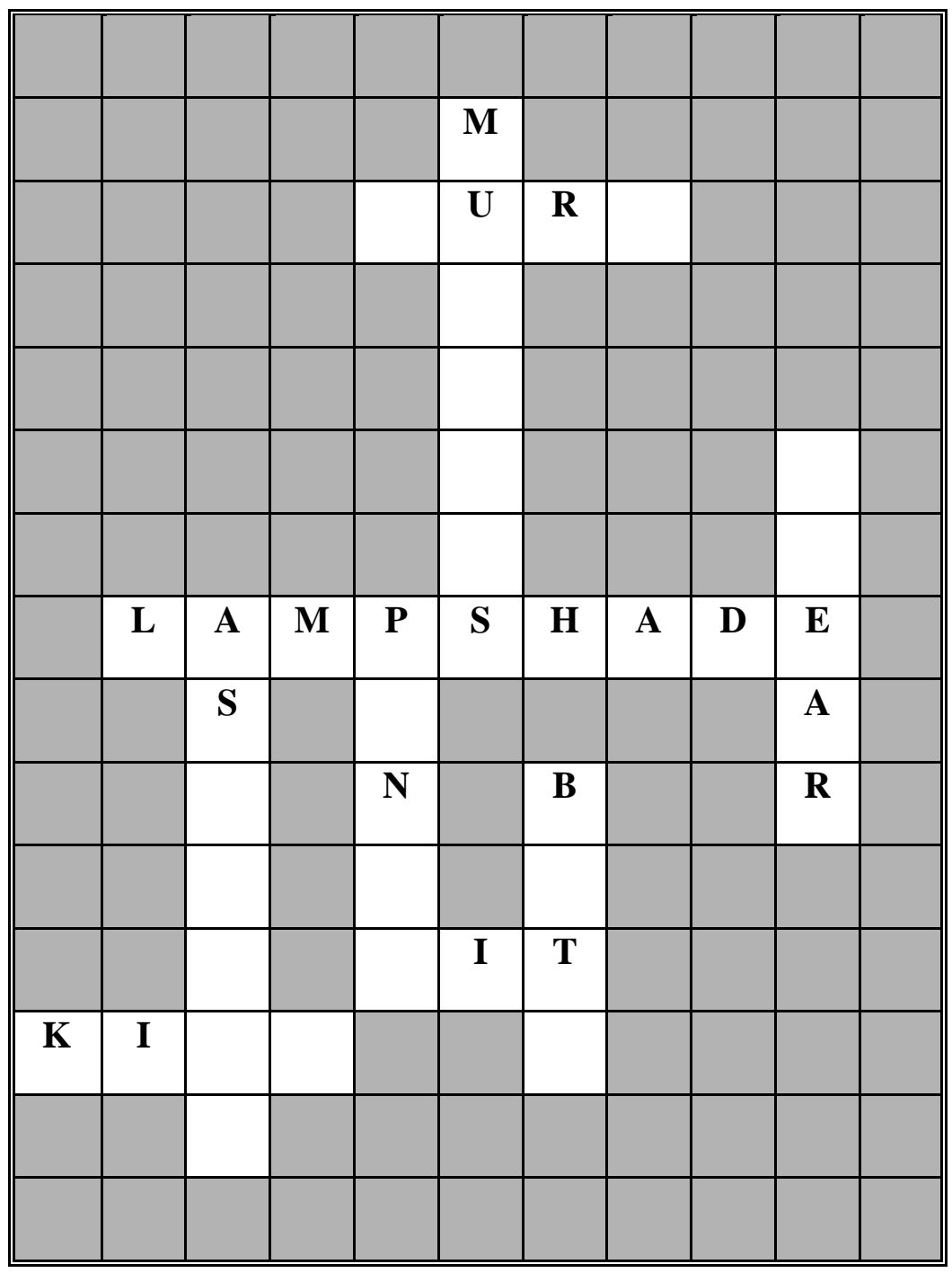

